\title{
Benign hereditary chorea
}

INSERM

\section{Source}

INSERM. (1999). Orphanet: an online rare disease and orphan drug data base. Benign hereditary chorea. ORPHA:1429

A rare, genetic, movement disorder characterized by early-onset, very slowly prog ressive choreiform movements that may involve variable parts of the body, typically agg ravated by stress or anxiety, in various members of a family. Additional variable manifestations include hypotonia, often resulting in psychomotor delay (including gait disturbances) and dysarthria, as well as myoclonus, dystonia, behavioral symptoms (ADHD, obsessivecompulsive disorder), learning difficulties (particularly in writing) and spasticity with hyperreflexia and/or flexor/extensor plantar reflexes. 